\title{
Effect of game design, goal type, and player numbers on the physiological and physical demands of hurling-specific small- sided games
}

\author{
Shane Malone \\ Technological University Dublin, Shane.Malone@TUDublin.ie \\ Kieran Collins \\ Technological University Dublin, kieran.collins@tudublin.ie
}

Follow this and additional works at: https://arrow.tudublin.ie/ittsciart

Part of the Sports Sciences Commons

\section{Recommended Citation}

Malone S, Collins KD. Effect of Game Design, Goal Type, and Player Numbers on the Physiological and Physical Demands of Hurling-Specific Small-Sided Games. J Strength Cond Res. 2017 Jun;31(6):1493-1499. doi: 10.1519/JSC.0000000000001628. PMID: 28538297.

This Article is brought to you for free and open access by the School of Science and Computing at ARROW@TU Dublin. It has been accepted for inclusion in Articles by an authorized administrator of ARROW@TU Dublin. For more information, please contact arrow.admin@tudublin.ie, aisling.coyne@tudublin.ie, gerard.connolly@tudublin.ie.

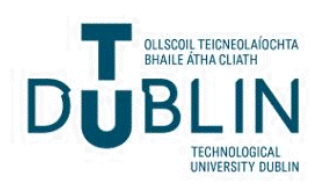




\title{
Effect of Game Design, Goal Type, and Player Numbers on the Physiological and Physical Demands of Hurling-Specific Small-Sided Games
}

\author{
Shane Malone and Kieran D. Collins \\ Gaelic Sports Research Center, Institute of Technology Tallaght, Tallaght, Dublin, Ireland
}

\begin{abstract}
Malone, S and Collins, K. Effect of game design, goal type, and player numbers on the physiological and physical demands of hurling-specific small-sided games. J Strength Cond Res 31 (6): 1493-1499, 2017-The current study examined the effect that game design modification, goal type, and player numbers on the running performance and physiological demands of small-sided hurling games (SSG). Forty-eight hurling players (age, $25.5 \pm 3.2$ years; height, $178.9 \pm 3.2 \mathrm{~cm}$; body mass, $78.5 \pm 4.5 \mathrm{~kg}$ ) performed 4 types of SSG (possession [P], normal play [NP], regular goals [RG] and small goals [SG]) in 4-a-side, 5-a-side, and 6-a-side formats. Heart rate (Polar Electro Oy) and global positioning system technology (VX Sport, 4-Hz, Lower Hutt) were used to analyze the physical and physiological differences between SSG. Total distance $(m)$, highspeed running distance $(\mathrm{m})\left(\geq 17 \mathrm{~km} \cdot \mathrm{h}^{-1}\right)$, very-high speed running distance $\left(\geq 22 \mathrm{~km} \cdot \mathrm{h}^{-1}\right)(\mathrm{m})$, peak and mean velocity $\left(\mathrm{km} \cdot \mathrm{h}^{-1}\right)$ were analyzed as an indicator of the physical demands of play. The 4-a-side SSG independent of game design and goal type resulted in a significantly higher relative exercise intensity compared with 5-a-side (mean change: $6 \pm 2 \% ; p=$ $0.001 ; d=1.9 \pm 0.2$; large) and 6 -a-side SSG independent of game design or goal type (mean change: $12 \pm 2 \% ; p=0.001$; $d=2.9 \pm 0.8$; very large). The 4 -a-side SG $(619 \pm 106-\mathrm{m}$ [419-735-m]) resulted in the highest distance when compared with all PP (mean change: $141 \pm 9 \mathrm{~m} ; p=0.05 ; d=1.9 \pm 0.3$; moderate) and RG (mean change: $119 \pm 39 \mathrm{~m} ; p=0.004 ; d=$ $2.1 \pm 0.8$; large). Similar trends were observed for 5 -a-side and 6-a-side games with SG resulting in increased total running performance. In conclusion, the current observations reveal that 4-a-side NP, SG, and RG have the highest physiological demands with 4-a-side SG having increased running performance in contrast to other game design and goal-type games. Furthermore, independent of game design and goal
\end{abstract}

Address correspondence to Shane Malone, shane.malone@ mymail.ittdublin.ie.

31(6)/1493-1499

Journal of Strength and Conditioning Research

(C) 2016 National Strength and Conditioning Association type, 4-a-side SSG show increased relative intensity compared with 5-a-side and 6-a-side SSG.

KEY WoRDS GPS, heart rate, team sport, conditioned games

\section{INTRODUCTION}

he development of aerobic capacity is an important consideration for conditioning coaches. Hurling is a team sport game played with stick (camán) and ball (sliothar), the skills required to successfully play the game are complex in nature. In essence hurling constitutes a form of intermittent exercise within which the timing of high-intensity efforts is acyclical following the ebb and flow of the game (28). This is a sport that requires players to engage in high-speed running, rapid acceleration, and deceleration movements intertwined with changes of directions, jumping, and body contacts. High aerobic capacity has been correlated to work rate during match play with high aerobic capacity reported to aid between bout recovery for players during high-intensity intermittent exercise (2). Therefore, there is a need for team sport players such as hurling players to be exposed to training programs that include elements of aerobic conditioning (5). The preparation for competition requires training to be viewed from an ergonomic perspective, where the training requirements are matched to the competitive demands of match play (27). Small-sided games represent a methodology of training that best allow the replication of match play demands from a hurlingspecific perspective $(16,22)$. Small-sided games (SSG) have been shown to represent an effective method of training to develop players capacity as they represent a multimodal method of training that combine technical, tactical, and physiological training stimuli simultaneously $(6,10,12,13,17,23)$. Previous investigations have shown heart rate (HR) responses of $86-98 \%$ HR maximum (22) during SSG where these exercise games have shown to improve aerobic capacity $(6,16)$ and physical match play running performance (24).

Within SSG, multiple characteristics can be manipulated to alter the physiological and running performance output by players. Several studies have analyzed the effects of modification of player number $(8,15,17)$, pitch size $(7-10,22,23)$, ball contacts $(29,30)$, coach encouragement (26), and different 
durations of play (9) on the physiological demands of players during SSG. Previously, Casamichana and Castellano (3) have reported differences in HR responses between different dimensions within SSG. Increased HR values were observed during large pitch dimensions compared with medium and small dimensions. However, the differences observed in these studies were relatively small. Indeed, well-controlled interventions by Kelly and Drust (18) comparing HR responses and technical demands of 5 vs.5 SSG played on small, medium, and large pitches have showed no difference in the HR profiles across varying pitch dimensions.

Recently, SSG have been manipulated to focus on games without space orientation where the main objective was to retain possession (possession play) or games with specific space orientation such as invasion-based games where the aim is to score in small or regular goals with or without goalkeepers. Currently, within a hurling-specific context, very few investigations have analyzed the effect that game design and type of goal have on the physiological and physical demands of SSG. Recent investigations in soccer have revealed that larger game formats are associated with a greater range of total distances and higher maximum speeds; these findings have been mostly related to relative player area (3).

Interestingly, the type of game played during SSG has been shown to impact the running performance of players. Recently, Gaudino et al. (10) observed that possessionorientated SSG resulted in greater total distances compared with SSG with goalkeepers. Casamichana et al. (4) showed that SSG based on possession play with small goals were more intense than SSG based on regular goals and goalkeepers. Gonzalez-Rondenas et al. (11) reported that 4-a-side SSG had a higher intensity when orientated around possession play. Interestingly, within the same study, in SSG when regular goals were utilized, games with larger player numbers ( 6 vs. $6>4$ vs. 4 ) were observed to have a higher game intensity. These findings were in contrast to previous literature that showed that possession-based games reduced the intensity of SSG game play (9). However, within team sport environments, such as hurling, possession retention is an important consideration and with differences in results reported in other team sports, there is a need to investigate the impact that game design and the type of goal have on the running performance and physiological demands of hurling-specific SSG. The aim of the current investigation was to examine the effect of game design modification, type of goal, and player numbers on the running performance and physiological demands of hurling-specific SSG in hurling players.

\section{Methods}

\section{Experimental Approach to the Problem}

Within the current study, the construct of SSG design and type was challenged, through comparing the running performance and physiological profile of players within similar SSG pitch dimensions $\left(150 \mathrm{~m}^{2}\right)$ across different game types and game designs. Comparisons were performed by examining 48 male hurling players during the 2015 competitive season. All players were part of the same squad, a top division 1 team who had previously won the county championship. A nonexperimental descriptive comparative design was used to examine the differences between SSG game designs and game types across both physiological and running performance. As work hypothesis, it was assumed that SSG consisting of normal play with regular goals on a 4 vs. 4 would elicit increased running performance and physiological demands compared with other game types because of this specific game design best representing hurling match. The running performance of players during the SSG was monitored using global positioning system (GPS) technology, which enables movement patterns in sports to be monitored in a valid and reliable manner (10,21-23). Moreover, HR analysis (22) was used for determining the physiological demands.

\section{Subjects}

Forty-eight hurling players (age: $25.5 \pm 3.2$ years; height: $178.9 \pm 3.2 \mathrm{~cm}$; body mass: $78.5 \pm 4.5 \mathrm{~kg}$; Yo-Yo intermittent recovery test level 2 (Yo-YoIR2): $1520 \pm 254 \mathrm{~m}$; maximum Yo-YoIR2 HR: $204 \pm 15 \mathrm{~b} \cdot \mathrm{min}^{-1}$; estimated $\mathrm{V}_{2}$ max: $65.97 \pm 5.98 \mathrm{ml} \cdot \mathrm{kg}^{-1} \cdot \mathrm{min}^{-1}$ ) volunteered to participate in the current study. All players were part of the same squad, a top division 1 team who had previously won the county championship, with a minimum playing experience of $8 \pm$ 3 years. The players trained 3 times a week throughout the investigation period. Written informed consent was obtained from the players before the commencement of the study and after local institutional ethical research design approval.

\section{Physiological Demand Measurement}

Physiological performance during SSG was assessed on the basis of HR analysis (22), which was recorded every 5 seconds using a telemetric device (Polar Team Sport System; Polar Electro Oy, Kempele, Finland). The HR maximum $\left(\mathrm{HR}_{\max }\right)$ of each player was determined by means of the Yo-YoIR2 (22). The mean HR ( $\left.\mathrm{HR}_{\text {mean }}\right)$ for each SSG were recorded and expressed as a percentage of individual maximum to provide an indication of the overall intensity of the SSG in relation to the mean and maximum HR obtained in the Yo-YoIR2 ( $\mathrm{HR}_{\text {mean }}$ and $\left.\% \mathrm{HR}_{\text {max }}\right)$. The coefficient of variation of $\mathrm{HR}$ responses $\left(\% \mathrm{HR}_{\max }\right)$ during small-sided games has been reported as $1.3-4.8 \%(26)$.

\section{Running Performance Measurement}

During all SSG participants wore an individual GPS unit (Issue: 330a, Firmware: 3.26.7.0; VXsport, Lower Hutt, New Zealand) sampling at $4 \mathrm{~Hz}$ and containing a triaxial accelerometer and magnetometer in all training sessions. The accuracy of this specific GPS unit has previously been communicated by Malone et al. (21) with acceptable 
reliability shown. The GPS unit (mass: 76 g; $48 \times 20 \times 87$ $\mathrm{mm}$ ) was encased within a protective harness between the player's shoulder blades in the upper thoracic spine region. Fifteen minutes before the commencement of training, the GPS device was fixed to the athlete, to establish a satellite lock training $(20,22,23)$. Proprietary software provided instantaneous raw velocity data at 0.25 -second intervals, which was then exported and placed into a customized Microsoft Excel spreadsheet (Microsoft, Redmond, WA, USA). The spreadsheet allowed analysis of distance covered $(\mathrm{m})$ and speed calculated $\left(\mathrm{km} \cdot \mathrm{h}^{-1}\right)$ in the following categories: total distance, high-speed running distance $\left(\geq 17 \mathrm{~km} \cdot \mathrm{h}^{-1}\right)$; very-high speed running distance $\left(\geq 22 \mathrm{~km} \cdot \mathrm{h}^{-1}\right)$, and peak velocity $\left(\mathrm{km} \cdot \mathrm{h}^{-1}\right)$.

\section{Small-Sided Games Layout and Design}

The SSG were performed at all training sessions from April to August during the competitive in-season period of the 2015 season. Training sessions were completed on the same pitch during the same time period of the day (6-8 PM). Before pitch session, a standardized warm-up of 20 minutes was completed consisting of technical skill execution, dynamic stretching, and jogging movements.

Table 1 reports the specific game dynamics of the SSG conducted during the observation period. Each SSG were supervised by the coaching team, every time the ball went out of play a replacement was readily available to allow for higher running performance and physiological demands in addition to increasing the continuity of the SSG. Furthermore, coaches encouraged a high press (all players when not in possession of the ball were encouraged to close the space allowed to the person they were marking to reduce the playing options of the person in possession of the ball) during SSG to best reflect the tactical set up of the team within

TABLE 1. Small-sided game design and layout for the duration of the observational period.*

\begin{tabular}{|c|c|c|}
\hline \multicolumn{3}{|c|}{ Small-sided game format } \\
\hline Player number & Game design & Type of Goal \\
\hline \multirow[t]{2}{*}{ 4-a-side } & Normal play & $\begin{array}{c}\text { Regular goal } \\
\text { Small goal }\end{array}$ \\
\hline & Possession & No goal \\
\hline \multirow[t]{2}{*}{ 5-a-side } & Normal play & $\begin{array}{c}\text { Regular goal } \\
\text { Small goal }\end{array}$ \\
\hline & Possession & No goal \\
\hline \multirow[t]{2}{*}{ 6-a-side } & Normal play & $\begin{array}{c}\text { Regular goal } \\
\text { Small goal }\end{array}$ \\
\hline & Possession & No goal \\
\hline
\end{tabular}

*All games completed on the same relative pitch dimension of $150 \mathrm{~m}^{2}$, with a 1:1 work-to-rest ratio and coach encouragement. match play environments. The SSG teams were picked based on positional associations with specific man marking encouraged throughout. This was to best reflect the manmarking nature of the game of hurling. During hurling match play, positional man marking takes place, for example, a half back will man mark a half forward and a full back will mark a full forward. Therefore, the application of a man-marking tactical concept was best suited to these specific SSG. Each SSG was standardized by time (4 minutes) with a 1:1 workto-rest ratio. The SSG were completed in a randomized manner to avoid ordering effects. Finally, all SSG were standardized by relative pitch area $\left(150 \mathrm{~m}^{2}\right)$ and followed the same tactical concept.

Four different types of SSG were completed by players, these consisted of the following:

- Possession play (PP): The aim of the teams within this SSG was to retain ball possession for as long as possible.

- Normal play (NP): The aim of the teams within this SSG was to retain possession and work as many goal scoring and point scoring opportunities as possible similar to match play dynamics.

- Regular goals (RG): The aim of the teams was to score goals and try not to concede a goal with regular goals (height $7 \mathrm{~m}$; width $21 \mathrm{~m}$ ) with goalkeepers present.

- Small goals (SG): The aim of teams was to score goals and try not to concede goals using small goals (height $4 \mathrm{~m}$; width $10 \mathrm{~m}$ ).

\section{Statistical Analyses}

All results are reported as mean and SDs with $90 \%$ confidence limits (mean $\pm S D[90 \% \mathrm{CL}]$ ). Before parametric analysis, all data were analyzed for normality using the Kolmogorov-Smirnov test. A 1-way analysis of variance was conducted with a Bonferroni post hoc analysis to evaluate the differences between physical and physiological demands of SSG (dependent variable) according to game design and goal type (PP vs. NP vs. RG vs. SG) and number of players (4-a-side, 5-a-side, 6-a-side) (independent variables). The level of statistical significance was set at $p \leq$ 0.05 . To make inferences about true values of the difference in the physical and physiological performance qualities of each SSG Cohen effect size (d) was reported. The uncertainty was expressed as $d \pm 90 \%$ CL. Effect sizes of $<0.2$; trivial, 0.2-0.6; small, 0.6-1.2; moderate, and 1.2-2.0; large were considered respectively. All statistical analyses were completed using the SPSS Version 22.0 (IBM Corporation, New York, USA).

\section{Results}

\section{Effect of Player Numbers}

Independent of game design and goal type, SSG HR responses were $194 \pm 14(184-200) \mathrm{b} \cdot \min ^{-1}, 188 \pm$ $17(170-192) \mathrm{b} \cdot \mathrm{min}^{-1}, 175 \pm 17(172-201) \mathrm{b} \cdot \mathrm{min}^{-1}$ corresponding to a relative exercise intensity of $94 \pm 4(90-98) \%$ $\mathrm{HR}_{\max }, 88 \pm 3(85-91) \% \mathrm{HR}_{\max }$ and $82 \pm 4(78-86) \%$ 


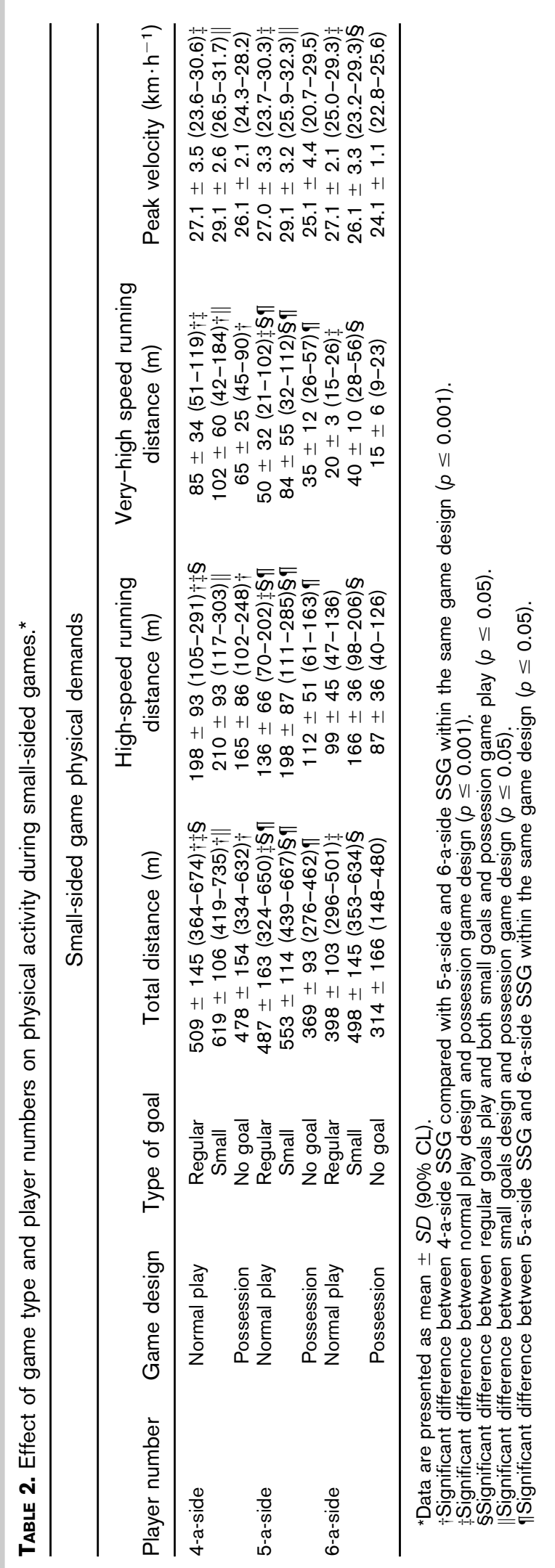

$\mathrm{HR}_{\max }$ for 4-a-side, 5-a-side, and 6-a-side SSG, respectively. The 4-a-side SSG independent of game design and goal type resulted in a significantly higher relative exercise intensity compared with 5-a-side (mean change: $6 \pm 2 \% ; p=0.001$; $d=1.9 \pm 0.2$; large) and 6-a-side SSG independent of game design or goal type (mean change: $12 \pm 2 \%$; $p=0.001 ; d=$ $2.9 \pm 0.8$; very large). Selected running performance measures are presented in Table 2. During SSG, players total distances were $535 \pm 132$ (478-619) $\mathrm{m}, 453 \pm 123$ (369503) $\mathrm{m}, 403 \pm 138$ (314-498) $\mathrm{m}$, corresponding to a relative work rate of $134 \pm 33(119-155) \mathrm{m} \cdot \mathrm{min}^{-1}, 113 \pm 31(92$ 138) $\mathrm{m} \cdot \mathrm{min}^{-1}$, and $100 \pm 35(79-124) \mathrm{m} \cdot \mathrm{min}^{-1}$ for 4 -a-side, 5-a-side, and 6-a-side SSG, respectively. The 4-a-side games resulted in the highest distance covered at high speed (191 \pm $62 \mathrm{~m}$ ) when compared with 5-a-side (mean change: $43 \pm$ $5 \mathrm{~m} ; p=0.04 ; d=0.9 \pm 0.2$; moderate) and 6-a-side (mean change: $74 \pm 23 \mathrm{~m} ; p=0.004 ; d=2.0 \pm 0.3$; large) games. Similar trends were observed for 5 -a-side games with increased distances at high (mean change: $31 \pm 29 \mathrm{~m} ; p=$ $0.05 ; d=0.6 \pm 0.3$; small) and very-high speed distances (mean change: $31 \pm 27 \mathrm{~m} ; p=0.04 ; d=0.3 \pm 0.1$; small) when compared with 6-a-side games.

\section{Effect of Game Design and Goal Type}

Selected physiological measures for the effect of game design and goal type are presented in Figure 1. Independent of player numbers, SSG HR responses were $192 \pm 12(180$ 204) $\mathrm{b} \cdot \min ^{-1}, 190 \pm 12(178-202) \mathrm{b} \cdot \min ^{-1}, 175 \pm 17(172$ 201) $\mathrm{b} \cdot \min ^{-1}, 175 \pm 17(172-201) \mathrm{b} \cdot \min ^{-1}$ corresponding to a relative exercise intensity of $93 \pm 3(90-96) \% \mathrm{HR}_{\max }$, $89 \pm 3(86-92) \% \mathrm{HR}_{\max }, 85 \pm 4(81-89) \% \mathrm{HR}_{\max }$, and $85 \pm$ $4(81-89) \% \mathrm{HR}_{\max }$ for $\mathrm{RG}, \mathrm{NP}, \mathrm{PP}$, and SG, respectively. When player number, game type, and design were considered, 4-a-side NP (95 \pm 6 [89-101] \%HR $\left.\mathrm{Hax}_{\max }\right), \mathrm{RG}(95 \pm$ $\left.6[89-01] \% \mathrm{HR}_{\max }\right)$ and $\mathrm{SG}\left(95 \pm 6[89-101] \% \mathrm{HR}_{\max }\right)$ game play resulted in the highest relative physiological demands, with these demands statistically higher compared with 4-a-side PP (mean change: $5 \pm 2 \% ; p=0.01 ; d=$ $1.3 \pm 0.3$; moderate). Similar trends were observed for NP $\left(92 \pm 3[89-95] \% \mathrm{HR}_{\max }\right)$ and $\mathrm{RG}(93 \pm 3[90-96] \%$ $\left.\mathrm{HR}_{\max }\right)$ for 5-a-side games, with these game designs resulting in higher relative intensities compared with PP (mean change: NP: $7 \pm 2 \% ; p=0.004 ; d=0.3 \pm 0.1$; small; RG: $8 \pm$ $2 \% ; p=0.004 ; d=0.3 \pm 0.1$; small) and SG (NP: mean change: $10 \pm 3 \% ; p=0.04 ; d=2.0 \pm 0.1$; large; RG: mean change: $10 \pm 3 \% ; p=0.04 ; d=2.0 \pm 0.1$; large). Regular goals $\left(90 \pm 6[84-96] \% \mathrm{HR}_{\max }\right)$ resulted in the highest relative intensity for 6-a-side games with these higher than $\mathrm{SG}$ (mean change: $11 \pm 3 \% ; p=0.001 ; d=2.0 \pm 0.1$; large), NP (mean change: $10 \pm 3 \%$; $p=0.04 ; d=1.9 \pm 0.1$; moderate), and PP (mean change: $10 \pm 3 \% ; p=0.04 ; d=1.9 \pm 0.3$; moderate), respectively. The effect of game design and goal type for selected running performance variables are presented in Table 2. When player number, game type, and design were considered, 4-a-side SG $(619 \pm 106 \mathrm{~m}$ 


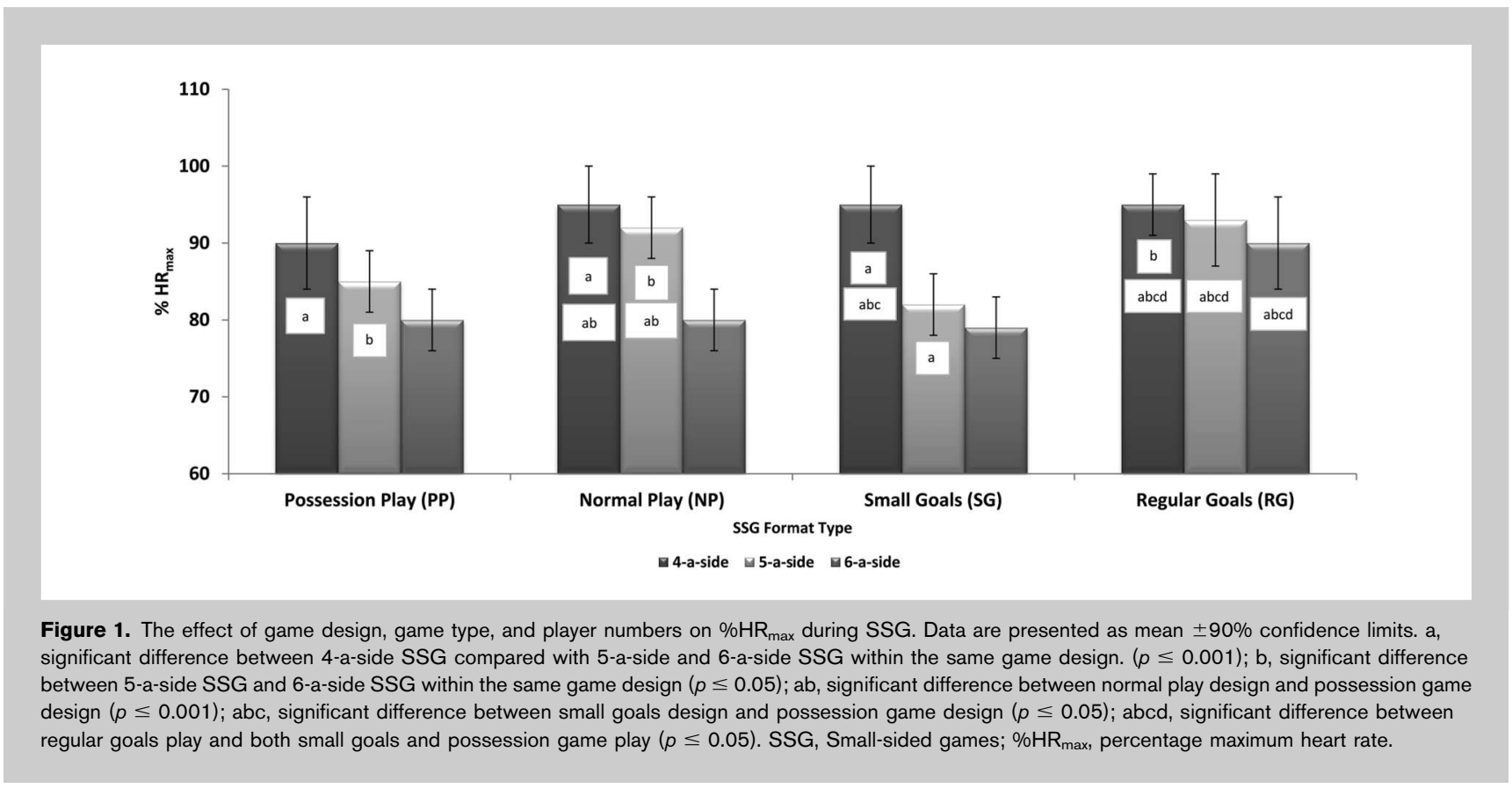

[419-735 m]) resulted in the highest distance compared with all PP (mean change: $141 \pm 9 \mathrm{~m} ; p=0.05 ; d=1.9 \pm 0.3$; moderate) and RG (mean change: $119 \pm 39 \mathrm{~m} ; p=0.004$; $d=2.1 \pm 0.8$; large). Similar trends were observed for 5 -aside and 6-a-side games with SG resulting in increased total running performance (Table 2).

\section{Discussion}

The aim of the current investigation was to observe the effect of game design, goal type, and player numbers on the physiological demands and running performance of hurlingspecific SSG, the investigation is the first to observe the impact game design, goal type, and player numbers have on SSG demands. The main finding of the study was that all the above have an impact on both the intensity and running performance during these games. Therefore, coaches should be aware that the design, player number, and goal type can be used as tools for modification of the demands of SSG within training sessions.

Recent studies have shown that SSG formats with a different number of players elicit different running performance and physiological characteristics (14,25). We observed that 4-a-side SSG resulted in higher relative intensity $\left(94 \pm 4[90-98] \% \mathrm{HR}_{\max }\right)$ independent of game design or goal type compared with other player number SSG. The current data show that 4-a-side hurling SSG result in a higher relative intensity compared with soccer-type SSG (1). The current results support previous findings within soccer cohorts that 4-a-side SSG result in higher intensity of play during SSG $(15,19,26)$ compared with 5 -a-side $(15,19)$ and 6-a-side SSG $(15,19)$. When the running performance of players was considered, similar trends were observed with 4-a-side SSG resulting in increased distances, this is despite the relative area of players remaining constant. Indeed 4-a-side SSG resulted in increased total distance, highspeed distance, and very-high speed distances compared with 5-a-side and 6-a-side games of the same relative pitch dimensions. These results are in contrast to previous literature that has reported no significant differences between total distances and high-speed distances when player numbers were manipulated (14). The current study is one of the first to show smaller player numbers during SSG result in increased running performance and physiological demands. This should be considered by conditioning coaches when preparing players during different phases of the competitive season within hurling cohorts.

Although previous research has shown an increase in HR response when pitch dimensions are altered (24), the current investigation has shown that the design types of SSG can have a significant impact on players' physiological demands and running performance. The current study has observed that $\mathrm{RG}\left(93 \pm 3 \% \mathrm{HR}_{\max }\right)$ and $\mathrm{NP}\left(89 \pm 3 \% \mathrm{HR}_{\max }\right)$ games resulted in increased physiological demands compared with the other game designs $\mathrm{PP}\left(85 \pm 4 \% \mathrm{HR}_{\max }\right)$ and $\mathrm{SG}(85 \pm$ $\left.4 \% \mathrm{HR}_{\max }\right)$ independent of playing numbers. This finding is in contrast to previous observations in soccer where small goal-based games resulted in higher intensities (11). This may be related to the dynamics of hurling where quick speed of ball movement, due to the stick and ball nature of game play, is a critical element of the game (28). This specific element of hurling play may have impacted the physiological demands of PP as the ball may have completed more work than player movement, therefore reducing the physiological demands of play. One of the novel aspects of the current 
study is the analysis of player numbers, game design, and goal type on the physiological demands and running performance within a hurling-specific context. The current study observed that 4-a-side NP $\left(95 \pm 6 \% \mathrm{HR}_{\max }\right), \mathrm{RG}(95 \pm 6 \%$ $\left.\mathrm{HR}_{\max }\right)$, and SG $\left(95 \pm 6 \% \mathrm{HR}_{\max }\right)$ resulted in the highest relative physiological demands being placed on players compared with other 4-a-side game designs. Interestingly, NP and RG game designs resulted in increased physiological demands for 5-a-side and 6-a-side games. These results are in contrast to previous literature that showed regular goal game designs resulted in lower relative intensities compared with possession-type game designs (11). These results suggest that a combination of different design types of sided games throughout the course of the training week is something that should be noted to maximize the physiological preparation of players and expose players to varying demands.

Our study observed that SG games resulted in the highest running performance independent of player number. Previously, Gaudino et al. (10) had observed that the total distance, high-speed distances, and peak velocity were higher in SSG with goalkeepers than SSG with a possession focus. Our findings are in contrast to these observations; interestingly in the present study SG games had no goalkeeper but still resulted in increased running performances. This can be related to players not being able to strike the ball for a point from distance that resulted in players being required to increase their interaction and running performance off the ball to work the ball into goal scoring opportunities. Indeed, these observations are in agreement with Casamichana et al. (4) who reported that SSG with small goals were more intense than SSG based on regular goals and goalkeepers. When peak velocity is considered, the current study observed that it was not necessary for large pitch dimensions to achieve a peak velocity, indeed the data showed that both 4-a-side and 5-a-side SSG with small goals and no goalkeepers resulted in increased peak velocities for players compared with other game types (Table 2). These findings are in contrast to previous observations in soccer (10) that report that when coaches are trying to focus on exposing players to peak velocity, that peak velocity is more pronounced in SSG with goalkeepers. The findings within the current investigation can be related to the game design of the small goal SSG with a focus and emphasis on running to support the man in possession because of no long strike for points being allowed within this specific game design and a focus on goal scoring being used; therefore, players had to work the ball up the pitch more through support play and increased off the ball running.

The current investigation should be considered with a number of limitations. With no technical data, it is very difficult to assess the efficiency of these specific SSG. It would be expected that each SSG would have its own specific technical outputs; however, although PP had reduced running and physiological parameters, it could be argued that this was because of increased technical outputs by players. Indeed, technical variables have been previously suggested to decide the outcome of competitive match play $(25,26)$. Additionally, Owen et al. (25) have shown technical and physical outputs of SSG vary based on pitch dimensions with larger SSG resulting in less technical outputs; however, these dimensions resulted in increased running performances. Therefore, it is important to understand the utility of SSG in the player preparation process. Therefore, future research within hurling should aim to investigate the specific technical outputs of SSG in conjunction with the running performance. Additionally, there is a need to investigate the running performance, physiological demands, and technical outputs of differing pitch dimensions, player numbers, and game designs within hurling-specific environments.

\section{Practical Applications}

Our investigation has important practical implications as it provides novel guidelines on how to use scientific information to maximize the training and delivery of field-based sessions to hurling players. We have shown that different game designs, goal types, and player numbers generate different metrics and therefore target different running and physiological components of performance. The aim of coaches is to overload specific areas of running and physiological performance in isolation rather than stimulating to lesser degrees every component within the same SSG. As a consequence, during field-based conditioning, it is paramount that training volume and intensity is fully understood within specific SSG, to best ensure appropriate physiological and performance adaptations. The current observations reveal that 4-a-side NP, SG, and RG have the highest physiological demands with 4-a-side SG having increased running performance in contrast to other game design and goal-type games. Furthermore, independent of game design and goal type, 4-a-side SSG show increased relative intensity compared with 5-a-side and 6-a-side SSG. The current study shows that hurling coaches should consider the goal type and number of players when constructing SSG-type training session to manipulate the running performance and physiological demands placed on players during these training games. Therefore, coaches should understand that each sport has its own specific demands that need to be reflected within training situations. As a result, hurling coaches should consider the application of SSG from other sports such as Gaelic football and soccer may not best prepare players for the specificity of hurling competition.

\section{REFERENCES}

1. Aguiar, M, Botelho, G, Lago, C, Macas, V, and Sampaio, J. A review of the effects of soccer small-sided games. J Hum Kinet 33: 103-113, 2012.

2. Buchheit, $M$ and Ufland, P. Effect of endurance training on performance and reoxygenation rate during repeated-sprint running. Eur J Appl Physiol 111: 293-301, 2011. 
3. Casamichana, D and Castellano, J. Time-motion, heart rate, perceptual and motor behaviour demands in small-sides soccer games: Effects of pitch size. J Sports Sci 28: 1615-1623, 2010.

4. Casamichana, D, Castellano, J, González, A, Garcia, H, and Garcia, $\mathrm{J}$. Physiological demands in small sided games on soccer with different orientation of space. Int J Sport Sci 7: 141-154, 2011.

5. Collins, DK, Reilly, T, Morton, JP, McRobert, A, and Doran, D. Anthropometric and performance characteristics of elite hurling players. J Athl Enhanc 3: 6, 2014.

6. Collins, K, Doran, DA, and Reilly, TP. Small sided games present an effective training stimulus in gaelic football. In: Science and Football VII: The Proceedings of the Seventh World Congress on Science and Football. Nunome, H, Drust, B, and Dawson, B, eds. London, United Kingdom: Routledge, 2013. pp. 379-383.

7. Corvino, M, Tessitore, A, Minganti, C, and Sibila, M. Effect of court dimensions on players' external and internal load during small-sided handball games. J Sports Sci Med 13: 297-230, 2014.

8. Dellal, A, Chamari, K, Owen, A, Wong, DP, Lago-Penas, C, and Hill-Haas, S. Influence of the technical instructions on the physiological and physical demands within small-sided soccer games. Euro J Sports Sci 11: 341-346, 2011.

9. Dellal, A, Chamari, K, Pintus, A, Girard, O, Cotte, T, and Keller, D. Heart rate responses during small-sided games and short intermittent running training in elite soccer players; a comparative study. J Strength Cond Res 22: 1449-1457, 2008.

10. Gaudino, P, Alberti, G, and Iaia, FM. Estimated metabolic and mechanical demands during different small sided games in elite soccer players. Hum Mov Sci 36: 123-133, 2014.

11. Gonzalez-Rodenas, J, Calabuig, F, and Aranda, R. Effect of the game design, the goal type and number of players on the intensity of play in small-sided soccer games in youth elite players. J Hum Kinet 49: 229-235, 2015.

12. Hill-Haas, SV, Coutts, AJ, Rowsell, GJ, and Dawson, BT. Generic versus small-sided game training in soccer. Int J Sports Med 30: 636642, 2009.

13. Hill-Haas, SV, Dawson, BT, Coutts, AJ, and Rowsell, GJ. Physiological responses and time-motion characteristics of various small-sided soccer games in youth players. J Sports Sci 27: 1-8, 2009.

14. Hill-Haas, SV, Dawson, BT, Coutts, AJ, and Rowsell, GJ. Timemotion characteristics and physiological responses of small-sided games in elite youth players: The influence of player number and rule changes. J Strength Cond Res 24: 2149-2156, 2010.

15. Hill-Haas, SV, Rowsell, GJ, Dawson, BT, and Coutts, AJ. Acute physiological responses and time-motion characteristics of two small-sided training regimes in youth soccer players. J Strength Cond Res 23: 111-115, 2009.
16. Impellizzeri, FM, Marcora, SM, Castagna, C, Reilly, T, Sassi, R, and Aiaia, F. Physiological and performance effects of generic versus specific aerobic training in soccer players. Int J Sports Med 27: $483-$ 492, 2006.

17. Jones, $\mathrm{S}$ and Drust, B. Physiological and technical demands of $4 \mathrm{v} 4$ and 8 v 8 in elite youth soccer players. Kinesiology 39: 150-156, 2007.

18. Kelly, DM and Drust, B. The effect of pitch dimensions on heart rate responses and technical demands of small-sided soccer games in elite players. J Sci Med Sport 12: 475-479, 2008.

19. Little, T and Williams, AG. Suitability of soccer training drills for endurance training. J Strength Cond Res 20: 316-319, 2006.

20. Maddison, R and Ni Mhurchu, C. Global positioning system: A new opportunity in physical activity measurement. Int J Behav Nutr Phys Act 6: 73, 2009.

21. Malone, S, Collins, DK, McRobert, AP, Morton, J, and Doran, DA. Accuracy and reliability of VXsport global positioning system in intermittent activity. Paper presented at the annual congress of the European College of Sport Science. Amsterdam, Netherlands, July 3, 2014.

22. Malone, $\mathrm{S}$ and Collins, $\mathrm{K}$. The physical and physiological demands of small sided games: How important is winning or losing? Int $J$ Perform Anal Sport 16: 422-433, 2016.

23. Malone, S, Solan, B, and Collins, K. The Influence of pitch size on running performance during gaelic football small sided games. Int $J$ Perform Anal Sport 16: 111-121, 2016.

24. Owen, AL, Wong, DP, Paul, D, and Dellal, A. Effects of periodized small sided game training intervention on physical performance in professional soccer. J Strength Cond Res 26: 2748-2754, 2012.

25. Owen, AL, Wong, DP, Paul, D, and Dellal, A. Physical and technical comparisons between various-sided games within professional soccer. Int J Sports Med 35: 286-292, 2014.

26. Rampinini, E, Impellizzeri, FM, Castagna, C, Abt, G, Chamari, K, Sassi, A, and Marcora, SM. Factors influencing physiological responses to small-sided soccer games. J Sports Sci 25: 659-666, 2007.

27. Reilly, T. An ergonomics model of the soccer training process. J Sports Sci 23: 561-572, 2005.

28. Reilly, T and Collins, K. Science and the gaelic sports: Gaelic football and hurling. Euro J Sports Sci 8: 231-240, 2008.

29. Silva, B, Garganta, J, Santos, R, and Teoldo, I. Comparing tactical behaviour of soccer players in 3 vs. 3 and 6 vs. 6 small sided games. J Hum Kinet 41: 191-202, 2014.

30. Vilar, L, Duarte, R, Silva, P, Chow, JY, and Davids, K. The influence of pitch dimensions on performance during small sided conditioned soccer games. J Sports Sci 32: 1751-1759, 2014. 